\section{Sulphinpyrazone-induced acute renal failure}

Many drugs have been associated with acute renal failure, which may present as acute tubular necrosis, interstitial nephritis, glomerulonephritis, arteritis, or intrarenal tubular obstruction. We report on a patient who developed acute tubular necrosis while taking sulphinpyrazone.

\section{Case report}

A 57-year-old man with no history of renal disease presented with acute renal failure. He had a two-year history of gout, for which he had taken sulphinpyrazone, and sulphinpyrazone had been restarted one week before admission for a recurrence of the disease. Three days before admission he had developed bilateral loin pain and oliguria. His only other medication were digoxin, frusemide, and amiloride. Physical examination showed mild fluid overload but no other abnormality.

Initial blood urea concentration was $16.9 \mathrm{mmol} / 1(102 \mathrm{mg} / 100 \mathrm{ml})$ and creatinine $0.72 \mathrm{mmol} / 1(8.1 \mathrm{mg} / 100 \mathrm{ml})$. There was no eosinophilia. Urine microscopy showed microscopic haematuria but no casts. Intravenous pyelography showed slightly enlarged kidneys with faint but persistent nephrograms. Cystoscopy and retrograde pyelography disclosed no abnormality. A renal biopsy specimen showed a mild focal increase in mesangial cell nuclei and matrix. Proximal tubules were normal. Distal tubules contained densely staining proteinaceous casts. There were foci of tubular atrophy with basement-membrane thickening. A moderate increase in interstitial tissue, without inflammation, was seen. Medium-sized arteries showed moderate fibrous intimal thickening, but arterioles were normal (figure). Immuno-

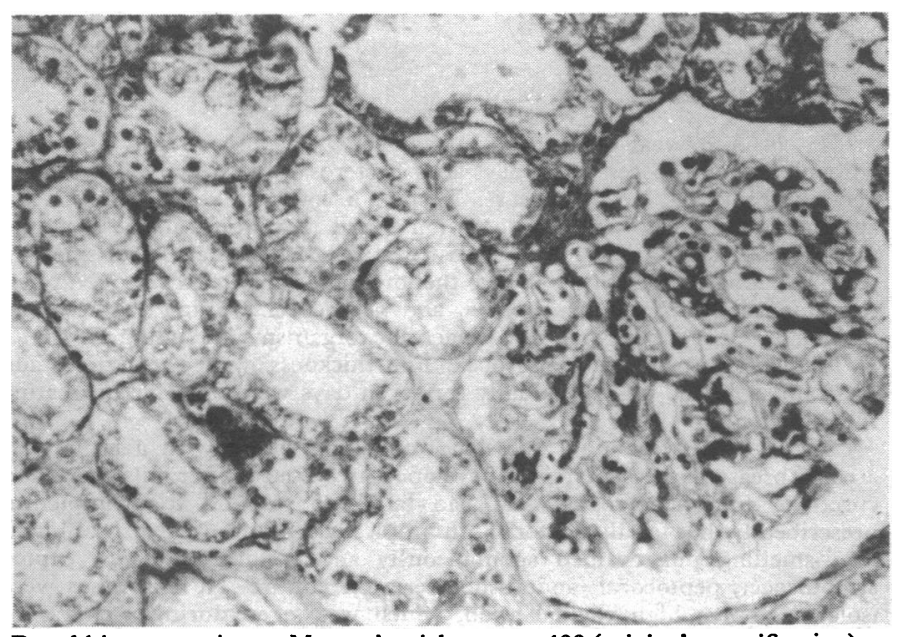

Renal biopsy specimen. Masson's trichrome $\times 400$ (original magnification).

fluorescence tests showed only $++\mathrm{C} 3$ in small vessels and hilar arterioles. Serum complement values and protein electrophoresis and immunoelectrophoresis patterns were normal. Urine protein electrophoresis and immunoelectrophoresis showed no evidence of myeloma. Tests for rheumatoid factor, antinuclear antibody, hepatitis B antigen and antibody, syphilis serology, leptospira serology, antistreptolysin $O$, and urine culture were all negative. Twenty-four-hour urinary protein excretion was initially $2 \cdot 7 \mathrm{~g}$ but 12 days after admission was $0.4 \mathrm{~g}$.

Urine output was initially $40 \mathrm{ml} / \mathrm{h}$ and had increased to over $250 \mathrm{ml} / \mathrm{h}$ by the third hospital day without diuretics. The serum creatinine concentration rose to a maximum of $0.79 \mathrm{mmol} / 1(8.9 \mathrm{mg} / 100 \mathrm{ml})$ on the second hospital day and then declined steadily to $0.12 \mathrm{mmol} / 1(1.4 \mathrm{mg} / 100 \mathrm{ml})$ on the seventh day. All treatment apart from sulphinpyrazone was continued throughout the hospital stay (although digoxin was suspended during the episode of acute renal failure). Five weeks after admission he was well with a creatinine concentration of $0.11 \mathrm{mmol} / 1(1.2 \mathrm{mg} / 100 \mathrm{ml})$

\section{Comment}

Sulphinpyrazone is a uricosuric and antiplatelet drug structurally related to phenylbutazone. It has recently been shown to decrease the risk of sudden death after acute myocardial infarction. ${ }^{1}$ Sulphinpyrazone-related acute renal failure has been reported only once but renal biopsy was not performed. ${ }^{2}$

In the present case of acute oliguric renal failure, acute tubular necrosis was found on biopsy with no evidence of acute interstitial nephritis. In addition there was no eosinophilia, rash, or fever to suggest an acute allergic phenomenon. The mechanism of this acute tubular necrosis is not clear but presumably represents acute tubular toxicity caused by the drug. The structural relation of sulphinpyrazone to phenylbutazone and the biopsy specimen changes in acute renal failure induced by phenylbutazone ${ }^{3}$ support a direct acute tubular toxicity by sulphinpyrazone. Other non-steroidal antiinflammatory drugs, however, have been reported as causing acute allergic interstitial nephritis. ${ }^{4}$

Acute urate nephropathy is a possibility. This has been reported with another uricosuric drug, ticrynafen, ${ }^{5}$ although not with sulphinpyrazone or probenecid despite widespread use. In the present case serum urate values were high, but this was most probably a consequence of the renal failure rather than a cause. No urate crystals were seen on urine microscopy. Although the renal biopsy specimens were not fixed in alcohol, the changes were not suggestive of urate nephropathy.

In view of the increasing use of sulphinpyrazone we report this case as a warning of a potentially serious toxic effect.

1 Anturance Reinfarction Trial Research Group. Sulfinpyrazone in the prevention of sudden death after myocardial infarction. $N$ Engl f Med $1980 ; 302: 250-6$.

2 Braun J. Abnormalities of urinary sediment and renal failure following sulfinpyrazone therapy. Arch Intern Med 1976;163:1060-1.

${ }^{3}$ Lipsett MB, Goldman R. Phenylbutazone toxicity: report of a case of acute renal failure. Ann Intern Med 1954;41:1075-9.

4 Brezin JH, Katz SM, Schwartz AB, Chinitz JL. Reversible renal failure and nephrotic syndrome associated with non-steroidal anti-inflammatory drugs. $N$ Engl f Med 1979;301:1271-3.

5 Bennett WM, Van Zee BE, Hutchings R. Acute renal failure from ticrynafen. $N$ Engl f Med $1979 ; 301: 1179-80$.

(Accepted 19 November 1980)

Department of Renal Medicine, Royal North Shore Hospital, St Leonards 2065, Australia

D S DURHAM, MB, BS, registrar

L S IBELS, MB, FRACP, nephrologist

\section{Peripheral corneal melting syndrome in association with psoriasis: a report of two cases}

Peripheral corneal melting syndrome is a rare disease consisting of marginal corneal thinning, sometimes to the extent of perforation. It is most often seen in association with rheumatoid arthritis and is also described in Sjögren's syndrome, polyarteritis nodosa, and Wegener's granulomatosis, ${ }^{1}$ but it may also occur in the absence of systemic disease. We describe two cases of peripheral corneal melting syndrome with psoriasis.

\section{Case reports}

CASE 1

A 62-year-old housewife was admitted to hospital as an emergency in March 1978 with a one-month history of generalised erythroderma, painful red eyes, blurred vision, and arthralgia affecting the neck, wrists, and shoulders. She had a 10-year history of stable, chronic plaque psoriasis affecting the knees and elbows, but the reason for its generalisation was not apparent. There was no other relevant previous medical, family, or drug history.

Examination showed generalised erythroderma with sheets of pustular psoriasis in many areas. She was icteric with gross ankle and sacral oedema and had synovial swelling of the wrists. During the first few days she was 